Global Proceedings Repository

American Research Foundation

ISSN 2476-017X

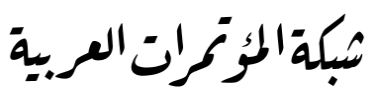

http://arab.kmshare.net/

Available online at http://proceedings.sriweb.org

Contemporary International Scientific Forum

for Educational, Social, Human, Administrative and Natural Sciences

"Present Vs Future Outlook"

$$
\begin{aligned}
& \text { الملتقى العلمي الدولي المعاصر } \\
& \text { للعلوم التربوية والاجتماعية والانسانية والادارية والطبيعية } \\
& \text { "نظرة بين الحاضر والمستقبل } \\
& 30 \text { - } 31 \text { ديسمبر -2019 - اسطنبول - تركيا }
\end{aligned}
$$

http://kmshare.net/isc2019

\title{
Electrical shock enhanced nucleic acids, proteins and specific activity of thymine nucleotide biosynthesis enzymes in stem callus of Sesamum indicum $\mathrm{L}$. \\ Nihal E. Al-Taee \\ Sajida A. Abood* \\ Mozahim K. Al. Mallah \\ * Department of Biology/College of Science/ University of Mosul/Iraq \\ E-mail: azizsajida@yahoo.com
}

\section{Abstract}

The present study revealed that exposure of stem derived callus of Sesamum indicum L. that grown on initiation medium Murashige and Skoog (MS) supplemented with BA and NAA at $2 \mathrm{mg} / \mathrm{l}$ and $1 \mathrm{mg} / \mathrm{l}$ respectively to electrical shocks at 200,250 and 300 volts of periods 25 and $50 \mathrm{msec}$. treatment enhanced a desirable changes of callus growth and development. The treatment $200 \mathrm{v} / \mathrm{msec}$ exposure had sustainable effect through enhancement the specific activity of TS,DHFR and SHMT enzymes which recorded $2.110,0.861$ and $0.196 \mu \mathrm{mol} / \mathrm{min} / \mathrm{mg}$ protein compared with $1.670,0.441$ and $0.139 \mu \mathrm{mol} / \mathrm{min} / \mathrm{mg}$ protein in control. The amounts of DNA and RNA were increased from $67 \mu \mathrm{g} / \mathrm{g}$ and $650 \mu \mathrm{g} / \mathrm{g}$ callus fresh weight respectively compared with $57 \mu \mathrm{g} / \mathrm{g}$ and $538 \mu \mathrm{g} / \mathrm{g}$ in control. On the other hand, the protein content and the fresh weight of callus were increased from $1.43 \mathrm{mg} / \mathrm{g}$ to $2.11 \mathrm{mg} / \mathrm{g}$ and $3.921 \mathrm{~g}$ to $9.055 \mathrm{~g}$ respectively. The result also predicted that electrical shock enhanced folate content $4.51 \mu \mathrm{g} / \mathrm{ml}$ to $7.97 \mu \mathrm{g} / \mathrm{ml}$. Whereas, the other electrical shock treatments decreased the specific activities of the above enzymes compared to $200 \mathrm{volt} / \mathrm{msec}$.

Key words: Sesamum indicum L. callus, Electrical shock, Thymine nucleotide enzymes 


\section{Global Proceedings Repository \\ American Research Foundation}

ISSN 2476-017X

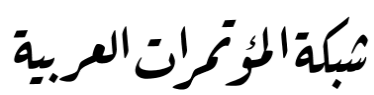

http://arab.kmshare.net/

Available online at http://proceedings.sriweb.org

الصدمة الكهربائية تحفز محتوى الاحماض النووية والبروتينات والفعالية النوعية لانزيمات نيوكليوتيد الثايمين في Sesamum indicum L. كالس سيقان السمسم

$$
\text { هال عزت الطائي }
$$

اظهرت نتائج الدراسـة الحالية ان تعريض الكالس المستحدث من سيقان السمسـم Sesamum indicum L. النامي في الوسط

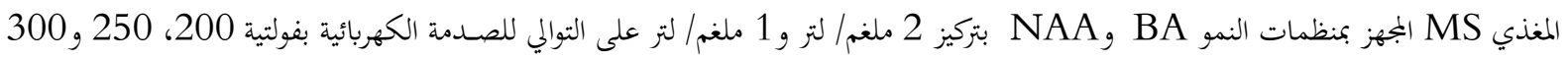
فولت ويمدد زمنية قدرها 25 و50 ملي ثانية/ معاملة حصــول تغيرات مرغوبة في نمو وتطور الكالس. تفوقت المعاملة 200 فولت/25 ملي ثانية في

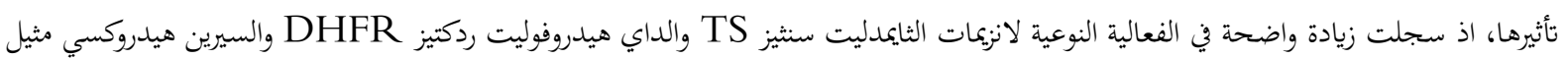
تررانسفريز SHMT في مستخلصات كالس سيقان السمسم مسـجلة 2.110 و 0.861 و0.196 مايكرومول/دقيقة/ملغم بروتين على التوالي قياســ بفعاليتها 1.670، 0.441 و0.139 مايكرومول/ دقيقة / ملغم بروتين في عينات المقارنة، وقد رافقها زيادة في كمية الاحماض النووية

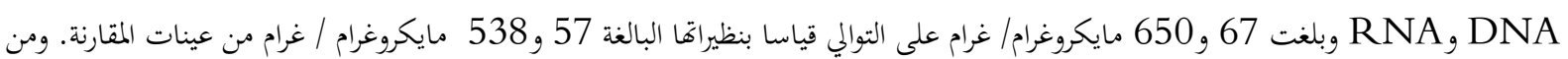

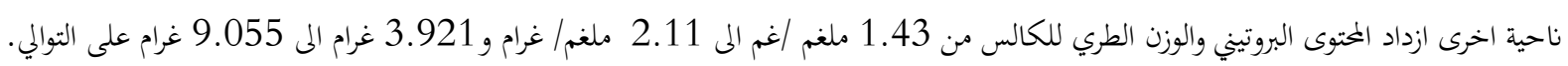

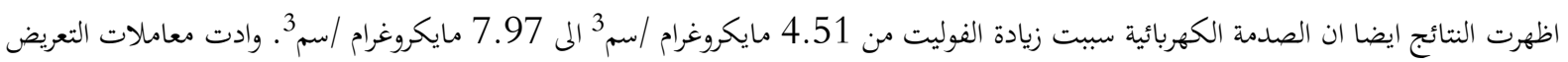
الاخرى للصــدمة الكهربائية الى خفض الفعالية النوعية للانزيمات المثــار اليها وكمية الاحماض النووية والبروتين وحامض الفولك وكذلك الوزن الطري للكالس مقارنة بعاملة 200 فولت/25 ملي ثانية. الكلمات الدالة: كالس السمسم، الصدمة الكهربائية، انزيمات نيوكليوتيد الثايمين. البحث مستل من اطروحة الباحث الاول.

المقدمة

يؤدي تعريض الخلايا للصدمة الكهربائية المتضمنة فولتيات معينة لمدد مختلفة بالمايكرو ثانية في إحداث فتحات بجهية مؤقتة في الأغشية البلازمية كافية لإدخال الجزيئات المرغوبة، ويعد تعريض الأنسجة النباتية لصدمة كهربائية تقنية فعالة تتفوق عن مثيلاتما من المعاملات الفيزياوية الأخرى كوفا طريقة

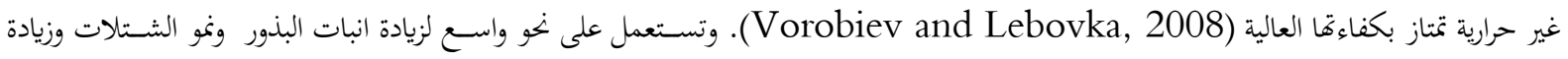

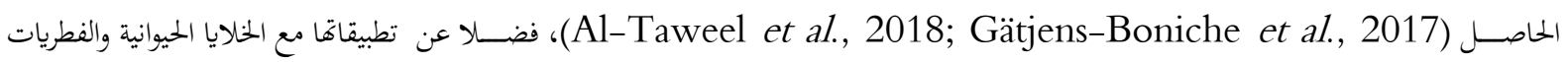

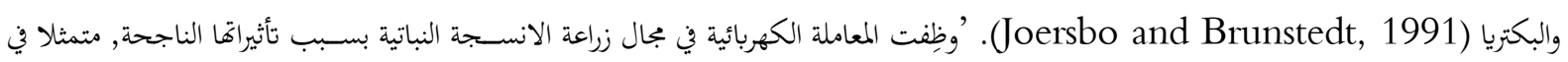

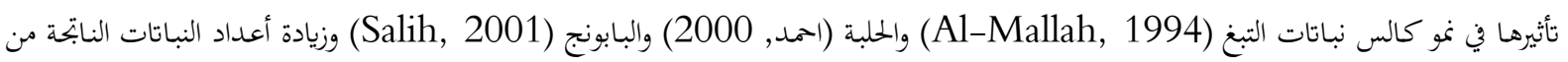
عنيب الذيب ومتواها من البروتين والكلوروفيل (Al-Mallah and Salih, 2003). وأدى تعريض الأجنة الجسمية المشتقة من كالس نبات القهوة 


\section{Global Proceedings Repository \\ American Research Foundation}

ISSN 2476-017X

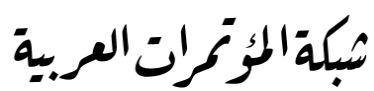

http://arab.kmshare.net/

Available online at http://proceedings.sriweb.org

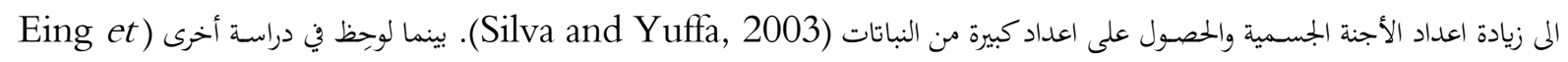

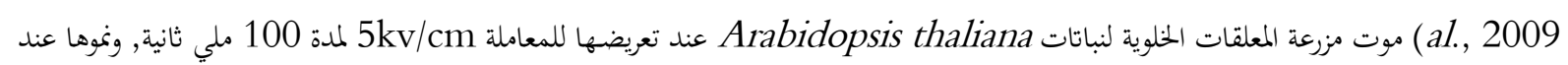
تعريضها للمعاملة ذاتما مدة 10 ملي ثانية. وعموما يلاحظ في غالبية الدراسات السابقة استعمال الفولتيات الواطئة التي تشجع نفاذية الأغشية الخلوية, وأثبتت إحدى الدراسات الحديثة بوساطة الفحوصات المجهرية لأنسجة البصل تحت ظروف المعاملة الكهربائية عن وجود علاقة بين تردد الفولتية المستخدمة

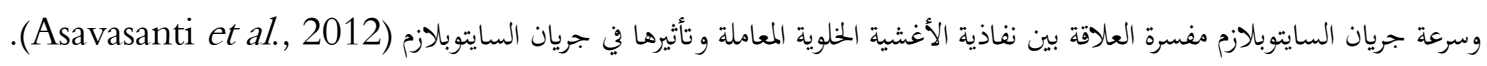

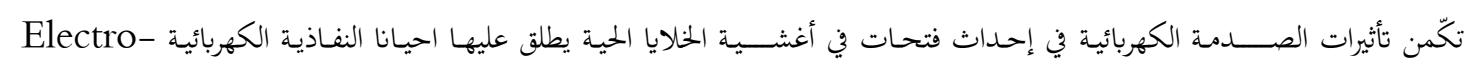

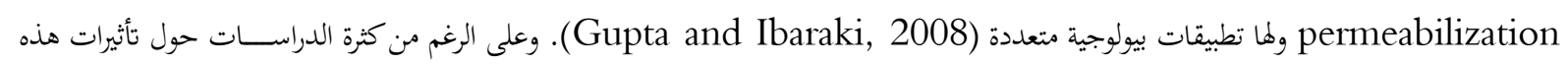

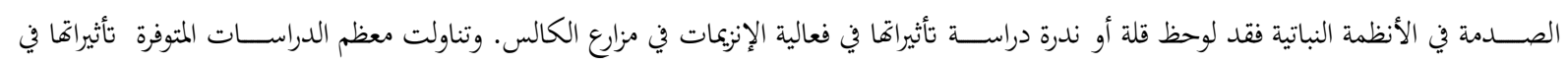

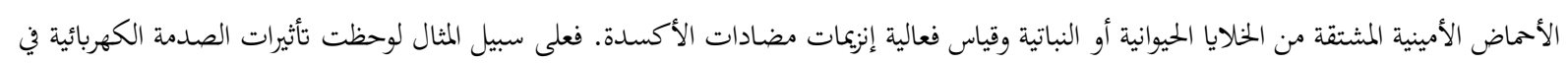

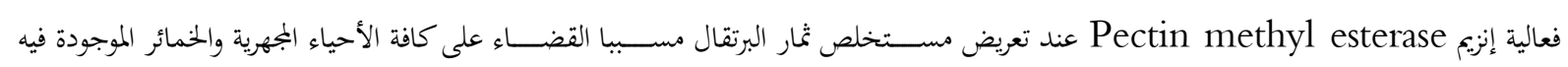
(Yeom et al., 2000) وزيادة فعالية إنزيمات التحلل المائي للبروتينات (Asavasanti et al., 2012). وغياب الدراسات التي تتناول تأثيراتما

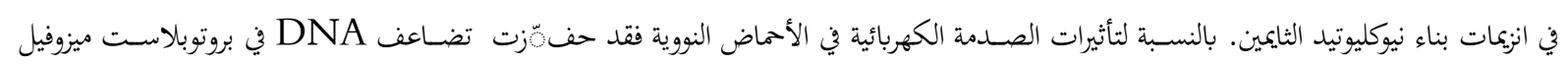

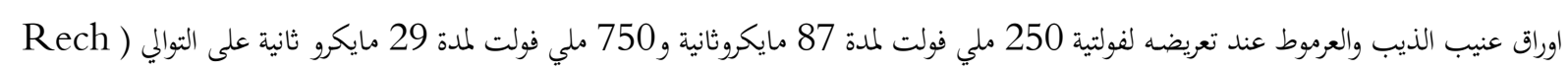
.) (et al., 1988 هدفت الدراسة الحالية الى التحري في انسجة كالس السمسم عن وجود مسار de novo لبناء نيوكليوتيد الثايمين احد نيوكليوتيدات بناء

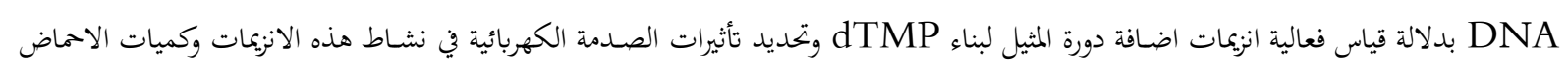
النووية والبروتينات والفوليت. المواد وطرائق العمل التعقيم السطحي للبذور والحصول على البادرات المعقمة جُهزت بذور السمسمم . Sesamum indicum L المعتمدة زراعتها في حقول محافظة نينوى من الأسواق المحلية وكانت نسبة إنباما

'عقمت مجموعة من البذور (500 بذرة) بغمرها في 50 ملليتر من الكحول الأثيلي 96\% مع التحريك لمدة دقيقتين ثم نقلت إلى 100

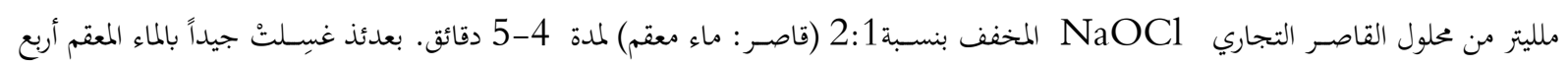

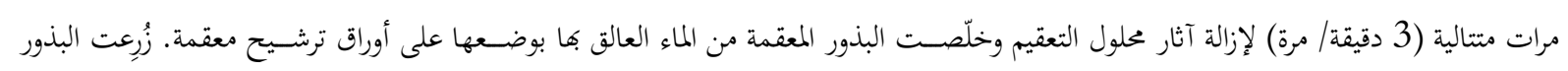

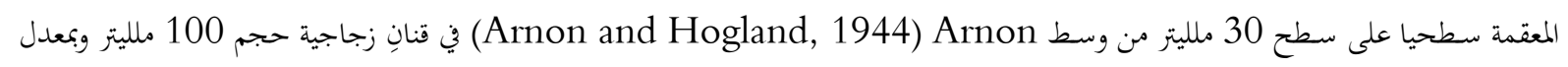

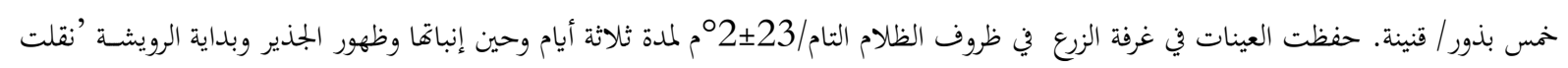
إلى ظروف إضاءة 16 ساعة وظلام 8 ساعات وشدة إضاءة 2000 لوكس لمواصلة نموها وإنتاج البادرات المعقمة وعلى نفس الدرجة اعلاه الماه. استحثاث مزارع كالس السيقان تحت الفلقية وإدامته 


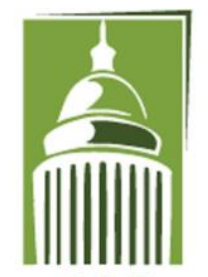

ARF

\section{Global Proceedings Repository \\ American Research Foundation}

ISSN 2476-017X

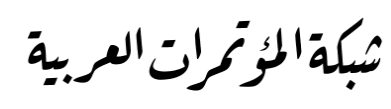

http://arab.kmshare.net/

Available online at http://proceedings.sriweb.org

جُهزتْ قطع السيقان تحت الفلقية بطول 1-1.5 سم تقريباً من بادرات السمسم المعقمة بعمر أسبوعين وزرعت بمعدل 3 قطع/ قنينة على الى

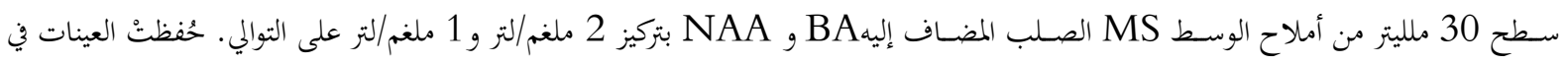

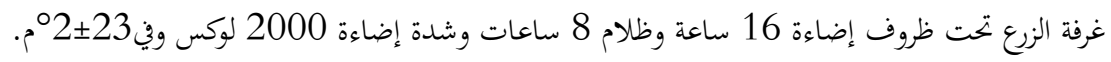
تعريض كالس السيقان تحت الفلقية للصدمة الكهربائية

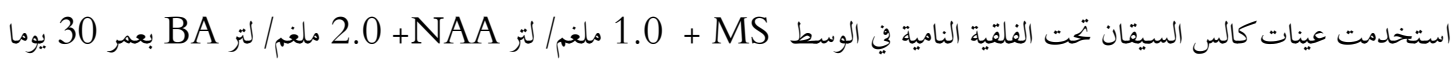
وبوزن غرام في بحربة تعريضـها للصــدمة الكهربائية لمعرفة تأثيرها في بعض المكونات الخلوية المهمة. وضـعتْ كل ثلاث عينات كالس في أذٍ واحد في خلية

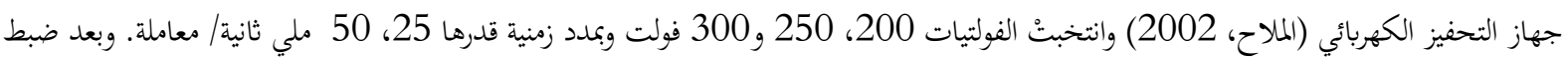

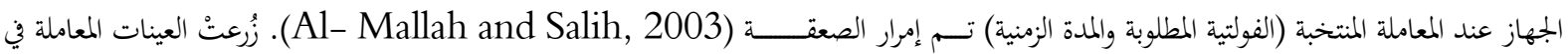

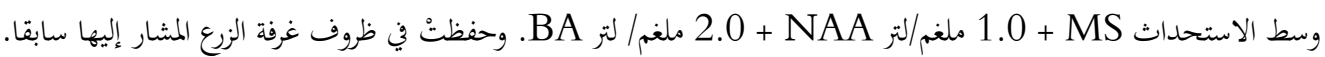
تقدير الأوزان الرطبة للكالس قدّرت الأوزان الرطبة للكالس من تحديد الفرق في وزن الكالس (غرام واحد) عند معاملته ووزنه بعد 30 يوماً من نموه بعد المعاملة. أستخلاص انزيمات بناء نيوكليوتيد الثايمين من الكالس المعامل فيزياوياً

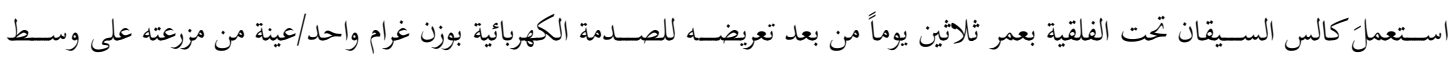
الاستحداث وسحقت كل عينة بصورة مستقلة في هاون خزفي مبرد في درجة صفر مئوية وأضيف إليه 30 ملليتراً من محلول بوتاسيوم-فوسفيت المنظم (50)

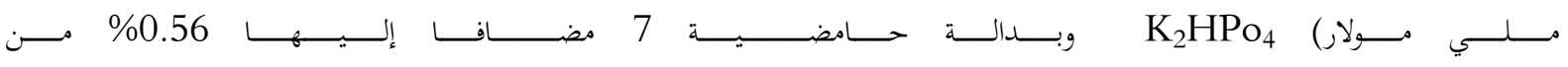
N-acetyl cysteine

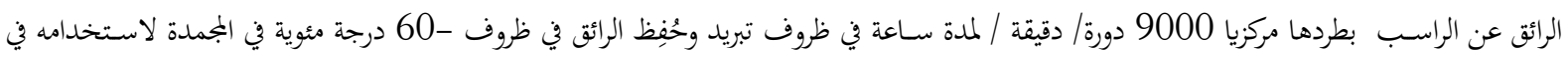

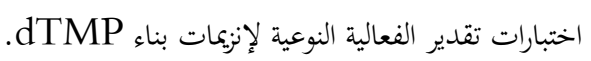

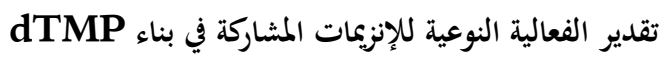
شملتُ تقدير الفعالية النوعية للإزنيمات الآتية:

إنزيم الثيميدليت سنثيز Thymidylate synthase

قيســتْ فعالية هذا الإنزيم من الزيادة في قيم الامتصـاص الضـوئي للمحلول عند الطول الموجي 340 نانوميتر بوجود الديوكسي يوريدين أحادي الفوسفيت (dUMP) كمادة أساس والتتراهيدروفوليت (Friedkin,1963) THF) كعامل مسـاعد بواسطة المطياف الضوئي عند 30 درجة مئوية

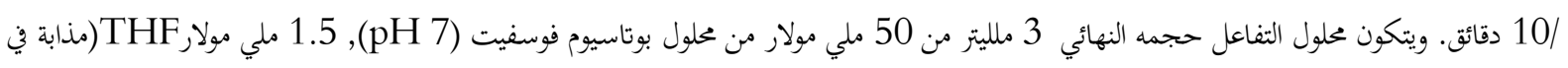

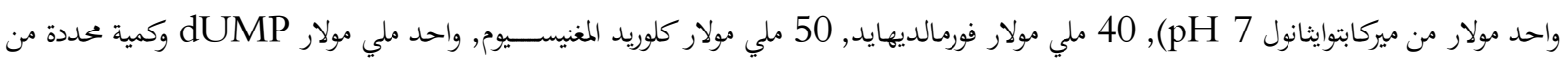

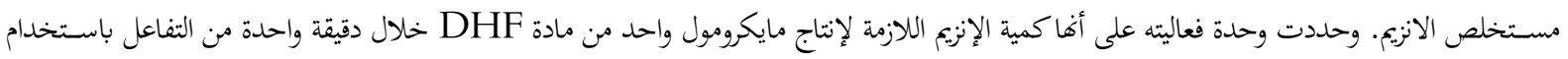

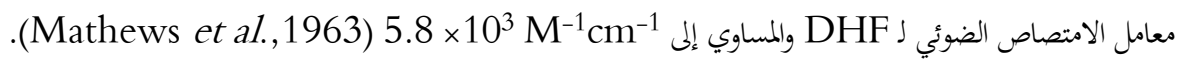
إنزيم الداي هيدروفوليت ردكتيز EC1.5.1.3) Dihydrofolate reductase) 


\section{Global Proceedings Repository \\ American Research Foundation}

ISSN 2476-017X

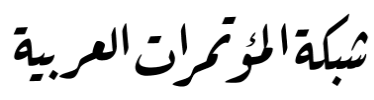

http://arab.kmshare.net/

Available online at http://proceedings.sriweb.org

قيستْْ فعالية هذا الإنزيم من معرفة الانخفاض الحاصل في قيم الامتصاص الضوئي ملحلول التفاعل عند الطول الموجي340 نانوميتر بوجود

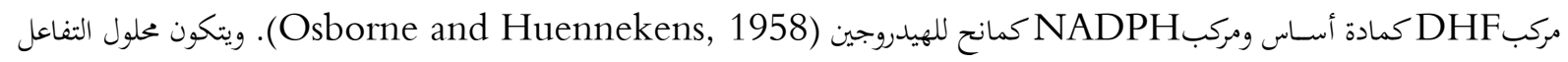
حجمه النهائي 3 ملليتر من 50 ملي مولار من المحلول المنظم بوتاسيوم فوسفيت (pH 6.8), 10 ملي مولار كبريتات المغنيسيوم, 10 ملي مولار

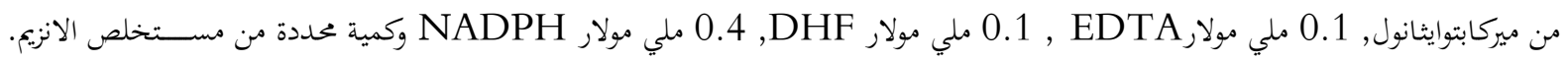

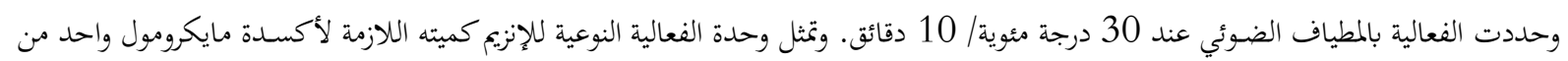

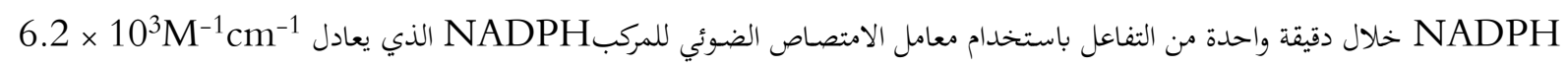
.(Mathews et al.,1963)

إنزيم السيرين هيدروكسي ميثايل ترانسفريز Serinehydroxymethyl transfrase) حُددتُ فعالية هذا الإنزيم من معرفة الانخفاض في قيم الامتصاص الضوئي للمحلول عند الطول الموجي 298 نانوميتر بوجود السيرين مادة

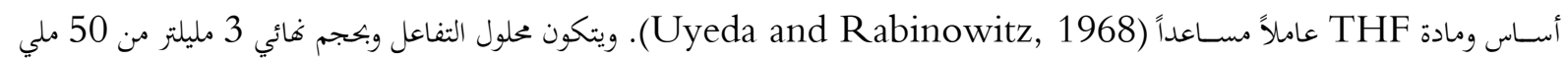

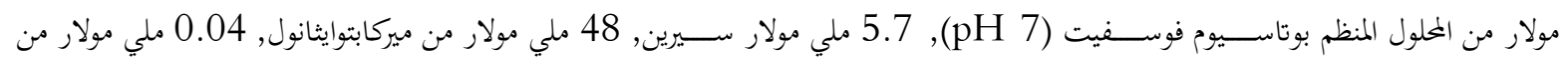

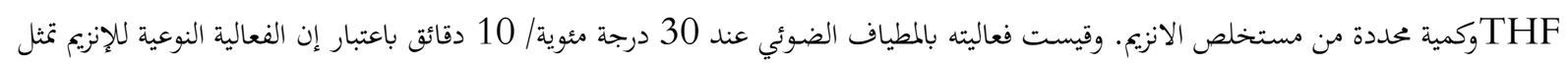

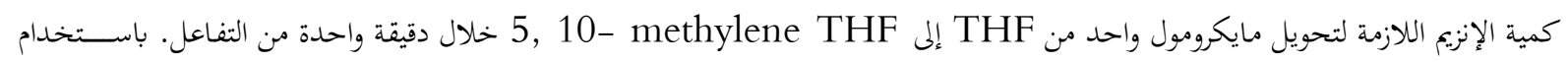

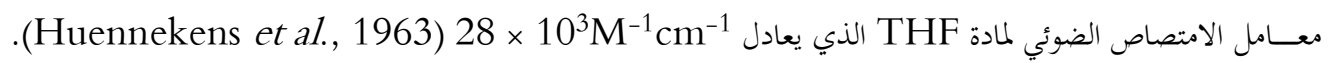
تقدير الختوى البروتيني (1951) Lowry طيقة قدرت كمية البروتين الكلي في عينات الكالس بعد 30 يوما من تعريضـهـ للصــدمة الكهربائية حس

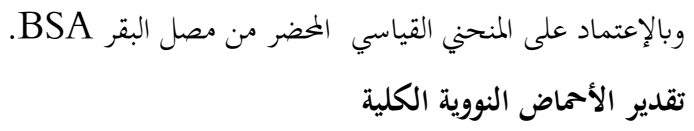

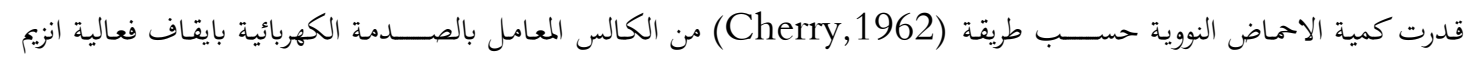
Nuclease وترسيب الاحماض النووية RNA, DNA وبالاعتماد على المنحنى القياسي المخضر من خلايا الخميرة النقية .أتبعتْ الطريقة القياسية

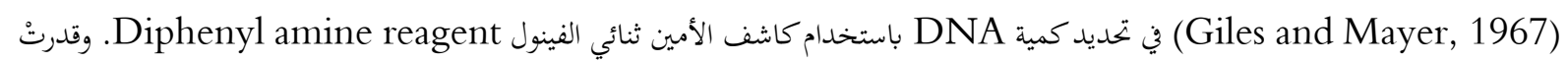
كمية الحامض النووي DNA من إيجاد الفرق بين شـدة الكثافة الضـوئية للمحلول عند الطول الموجي 700 نانوميتر والطول الموجي 595 نانوميتر

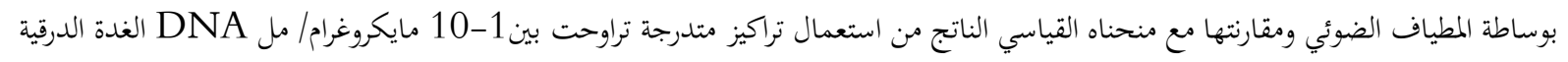

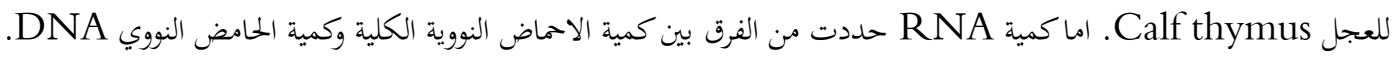
استخلاص الفوليت الكلي وتقدير كميته في مستخلص البادرات والكالس

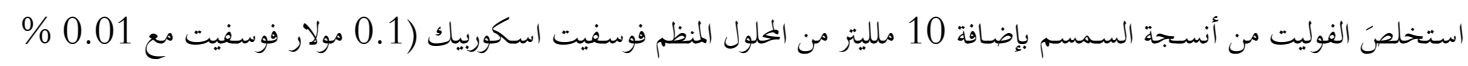

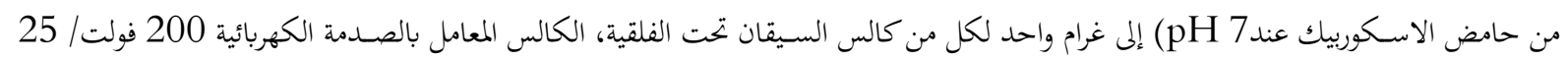
ملي ثانية، فضلاً عن السيقان تحت الفلقية للبادرات المعقمة. وضع المستخلص في مام مائي بدرجة 100مئوية ولمدة 10 دقائق لثنبيط فعالية انزيمات 


\section{Global Proceedings Repository American Research Foundation}

ISSN 2476-017X

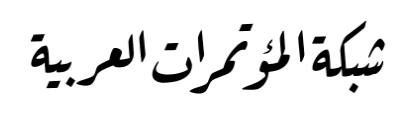

http://arab.kmshare.net/

Available online at http://proceedings.sriweb.org

الكونجوكيز Gongoconase. عزل الرائق عن الراسب بعملية الطرد المركزي بسرعة 6000 دورة/ دقيقة لمدة 10 دقائق واخذ الرائق وضبط pH عند 4.5 (Batra et al., 1977). وقُدرِتْ كمية الفوليت (Gao et al., 2010) من قياس كمية حامض الفوليك الكلية بواسطة HPLC باستخدام عمود الفصل

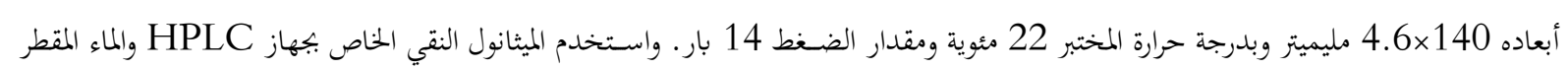
بنسبة 40: 60\% مع اضافة 0.3 من حامض الخليك الثلجي كمذيب في الطور المتحرك بعد ترشيحه وطرد الغازات منه باستخدام جهاز التزددات

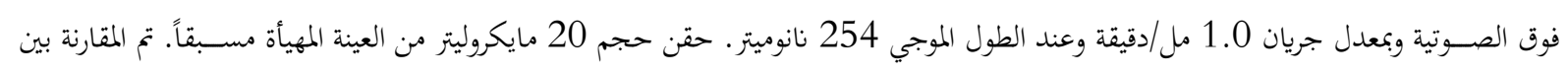

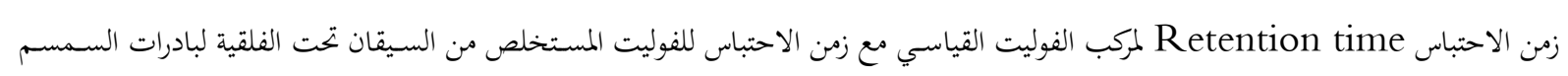

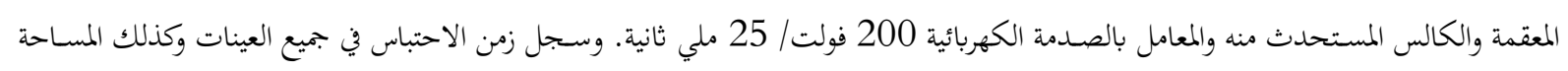
تحت المنحني. النتائج

تأثيرات الصدمة الكهربائية في كتلة الكالس ووزنه الرطب ومختواه البروتيني

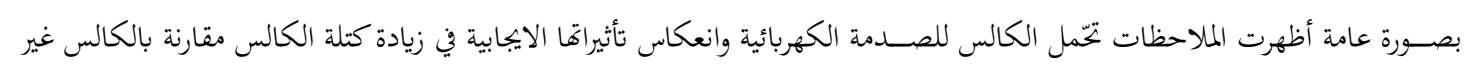

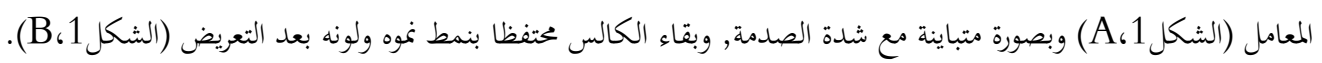

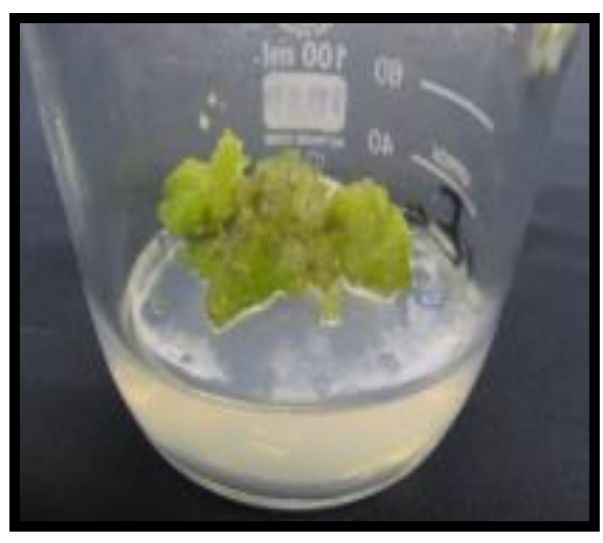

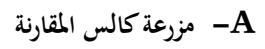

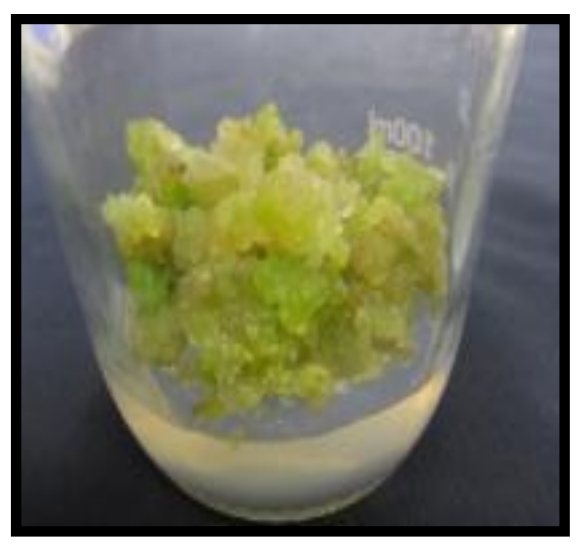

B- Bالس الصدمة 200 فولت/25 ملي ثانية

الشكل (1): كالس السيقان تحت الفقية للسمسم .Sesamum indicum L بعد ثلاثين يوما من تعريضه للصدمة الكهربائية ومو في وسط فيط

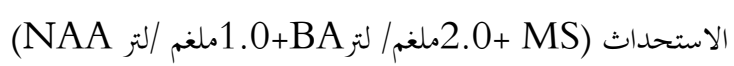

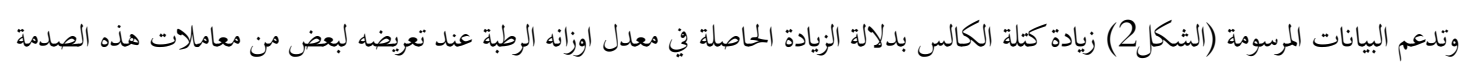

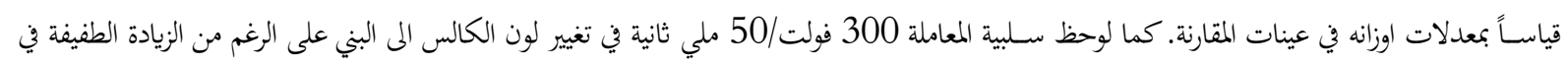
وزنه الرطب ومحتواه من البروتينات.

وعموما فقد اوضـحت النتائج ان انماط الزيادة في كمية البروتين في هذا الكالس (الشـكل2, B م) اتخذت أنماطاً مشـاهة لأنماط الزيادة في

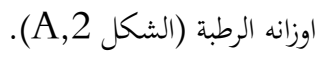

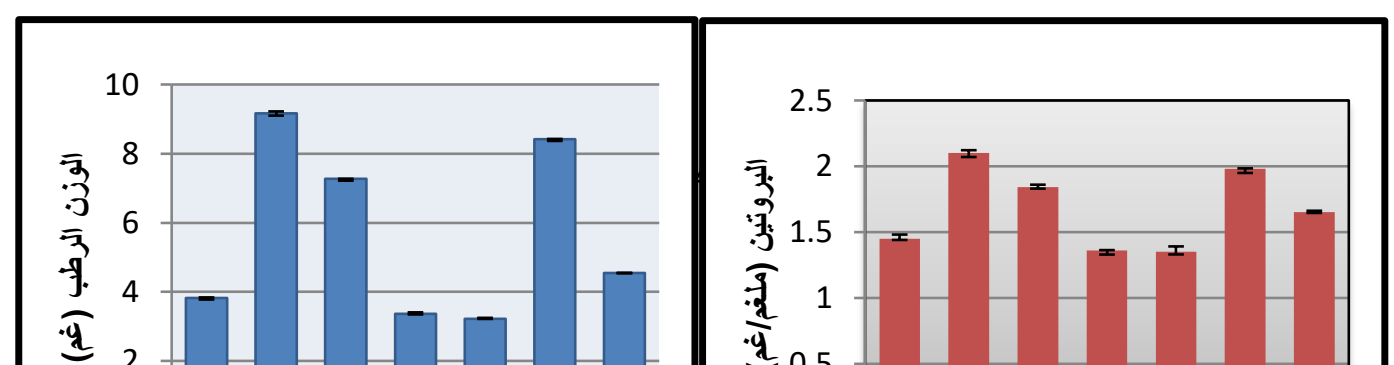




\section{Global Proceedings Repository \\ American Research Foundation}

ISSN 2476-017X

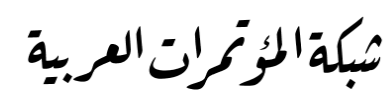

http://arab.kmshare.net/

Available online at http://proceedings.sriweb.org

A

\section{B}

$$
\text { الأوزان الرطبة }
$$

كمية البروتينات

الشكل (2): انعكاسات تأثير الصدمة الكهربائية في الاوزان الرطبة(A) وكمية البروتينات (B) في كالس السيقان تحت الفلقية للسمسم Sesamum الفمبة النامي في وسـط الاسـتحداث (indicum L.

$$
\text { معدل خمس مكررات للوزن الرطب وثلاث مكررات لكمية البروتين. }
$$

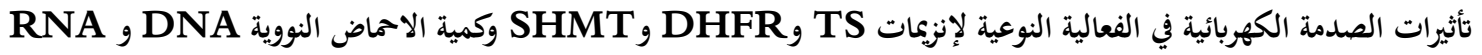

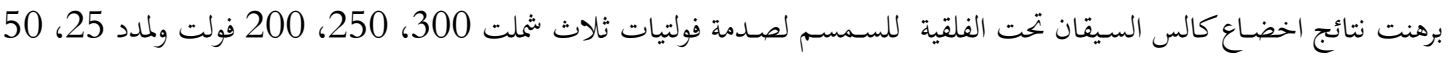
ملي ثانية عن تحفيزها للفعالية النوعية لإنزيعات بناء نيوكليوتيد dTMP في هذا الكالس بدلالة سـلوك نموه على وسـط الادامة (MS (-MS 2.0 ملغم / التر BA+ 1.0 ملغم/ لتر NAA). ولوحظ تباين مســتوى التحفيز مع تباين الفولتية ومدة التعريض. وبصـــورة عامة أظهرت الفولتية 200 بمدة

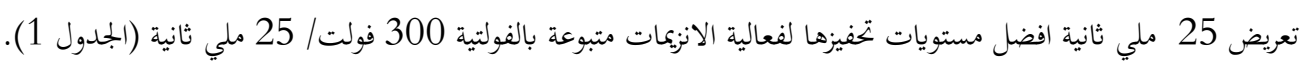

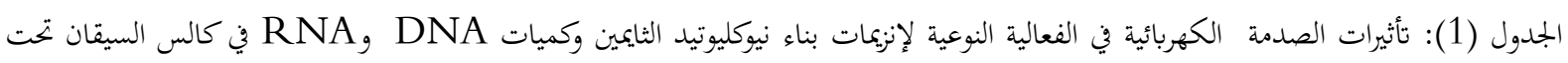
Sesamum indicum L.

\begin{tabular}{|c|c|c|c|c|c|}
\hline \multicolumn{2}{|c|}{ 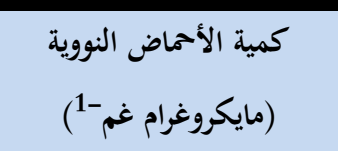 } & \multicolumn{3}{|c|}{ 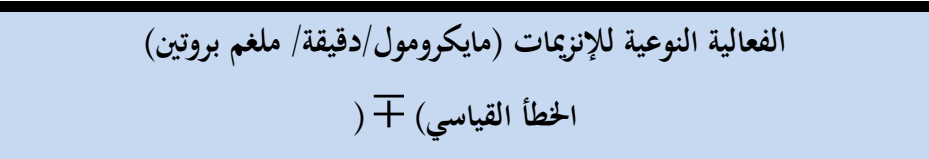 } & \multirow{2}{*}{ فولت المعاملة ملي ثانية } \\
\hline RNA & DNA & SHMT ${ }^{* * * *}$ & DHFR ${ }^{* *}$ & TS* & \\
\hline $538 \mathrm{~b}$ & $57 \mathrm{~b}$ & $0.002 \mp_{0.139}$ & $0.010 \bar{\mp}_{0.441}$ & $0.309 \bar{\mp}_{1.67}$ & المقارنة \\
\hline $650 \mathrm{ab}$ & $67 a$ & $0.011 干_{0.196}$ & $0.031 \bar{\mp}_{0.861}$ & $0.093 \bar{F}_{2.110}$ & $25 / 200$ \\
\hline $580 \mathrm{ab}$ & $60 \mathrm{~b}$ & $0.003 干_{0.176}$ & $0.051 \bar{\mp}_{0.630}$ & $0.085 \bar{\mp}_{1.911}$ & $50 / 200$ \\
\hline $449 c$ & $45 \mathrm{c}$ & $0.013 \mp_{0.121}$ & $0.005 \bar{\mp}_{0.462}$ & $0.061 \bar{\mp}_{1.076}$ & $25 / 250$ \\
\hline $435 c$ & $48 \mathrm{c}$ & $0.021 \bar{\mp}_{0.093}$ & $0.011 \bar{\mp}_{0.325}$ & $0.074 \bar{\mp}_{1.082}$ & $50 / 250$ \\
\hline $620 \mathrm{~b}$ & $61 \mathrm{~b}$ & $0.020 \mp 0.156$ & $0.041 \bar{\mp}_{0.723}$ & $0.142 \bar{\mp}_{1.915}$ & $25 / 300$ \\
\hline $229 \mathrm{~d}$ & $23 \mathrm{e}$ & $0.001 \bar{\mp}_{0.032}$ & $0.020 \bar{\mp}_{0.044}$ & $0.021 \bar{\mp}_{0.097}$ & $50 / 300$ \\
\hline
\end{tabular}
الفلقية للبن 


\section{Global Proceedings Repository \\ American Research Foundation}

ISSN 2476-017X

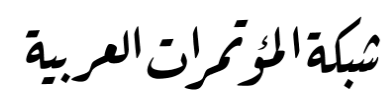

http://arab.kmshare.net/

Available online at http://proceedings.sriweb.org

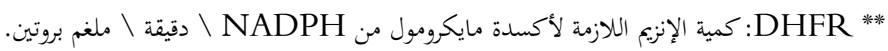

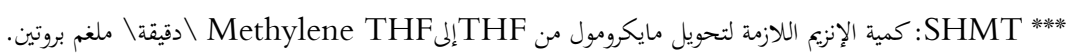

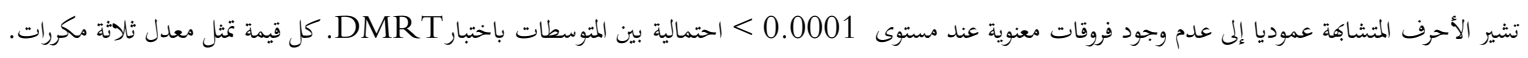

يلاحظ من بيانات الجدول اعلاه انفراد الصسـدمة 200 فولت/ 25 ملي ثانية في دعم نشــاط انزيمات SHMTو DHFR, TS

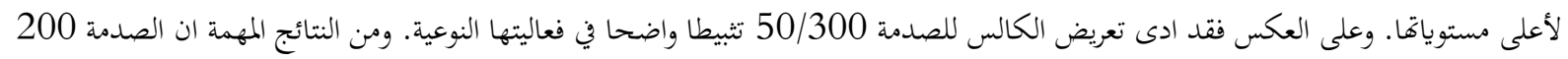

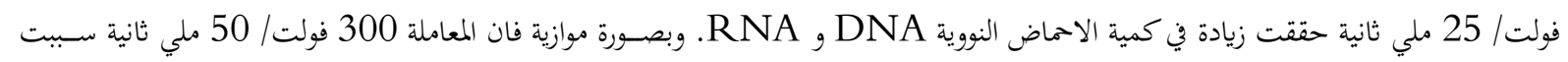

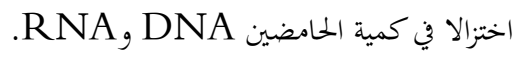

تأثير الصدمة الكهربائية في محتوى الكالس من الفوليت أظهرت النتائج أن تركيز الفوليت المســتخلص من كالس الســيقان تحت الفلقية بعمر 60 يوم كان أكثر من تركيزه في ســـيقان بادرات

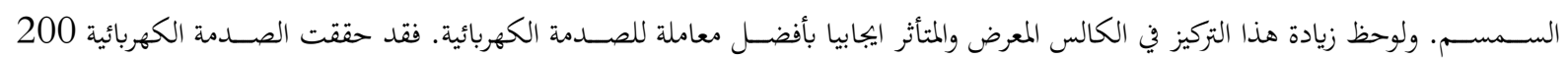
فولت/25 اعلى تركيز للفوليت اذ بلغ 7.97 مايكروغرام/مل قياسا بمعاملة المقارنة 2.38 مايكروغرام/ مل (الشكل، 2).

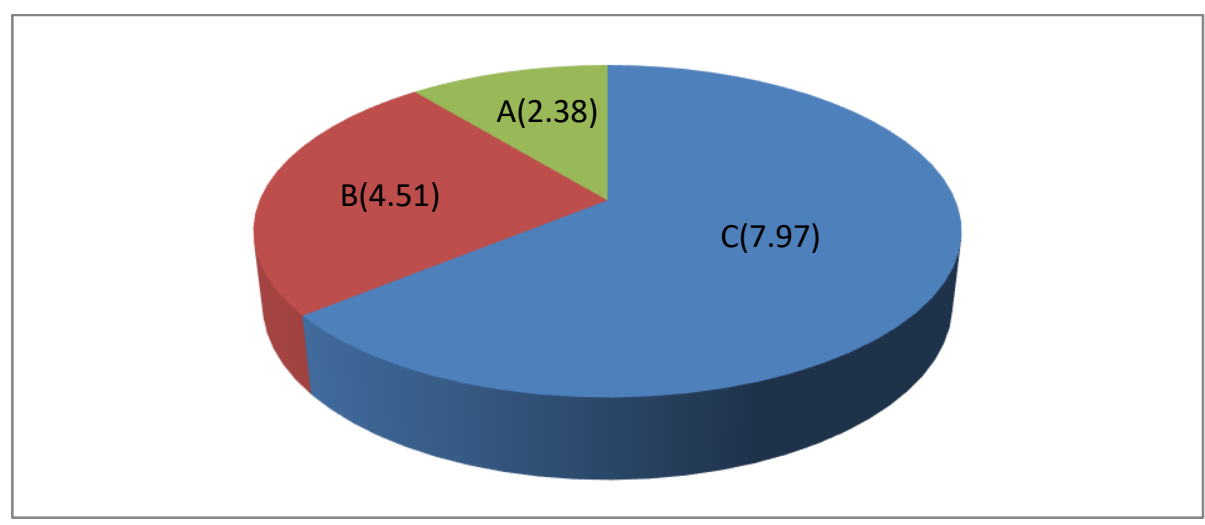

-A

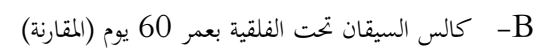

C- C كالس الصدمة الكهربائية (200 فولت/25 ملي ثانية)

الشكل (2): تقدير تركيز الفوليت في مستخلصات كالس السيقان تحت الفلقية للسمسم . Sesamum indicum L المتأثر ايبابيا بالصدمة الكهربائية باستخدام كروماتوكرافيا السائل عالي الاداء.

المناقشة

Santi and Danenberg, ) ان صعوبة دراسة فعالية انزيمات دورة اضافة المثيل في النباتات قد تعزى الى الانخفاض الكبير في فعالياتها 1984) وهذا يعود الى الانخفاض في معدلات تضـاعف DNA فيها (Blakley, 1969), في حين وجد ان الفعالية تزداد في الحلايا السـريعة

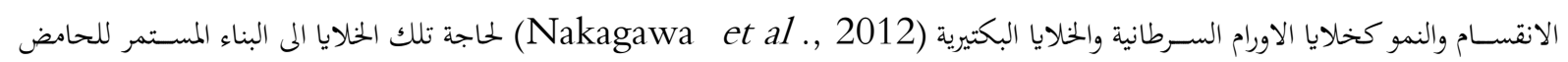




\section{Global Proceedings Repository American Research Foundation}

ISSN 2476-017X

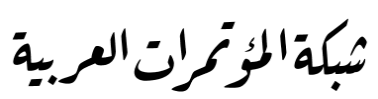

http://arab.kmshare.net/

Available online at http://proceedings.sriweb.org

DNA وبذلك يَّّد الكالس المستحدث احد الانسجة الناجحة في عزل وقياس فعالية الانزيمات بضمنها انزيمات دورة اضافة المثيل من كالس زهرة الشـمس (Mohammad et al., 1989a) وكالس الخس (محمد وأخرون, 2007) وانزيم الكلوتاميت ديهايدروجنيز في كالس الحبة السـوداء

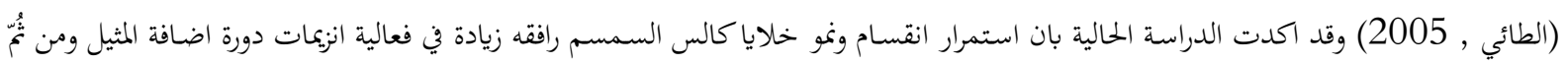
زيادة في محتوى الخلايا من الامماض النووية والبروتينات والفوليت الضرورية لعملية الانقسام, فضلا عن زيادة فعالياتما بواسطة تاثير الصدمة الكهربائية

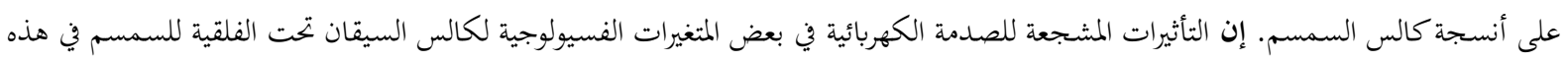

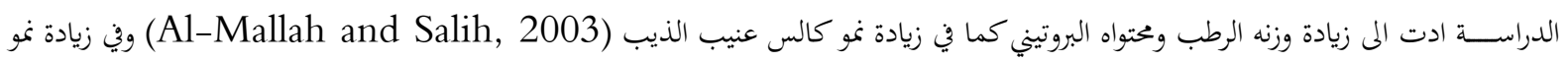

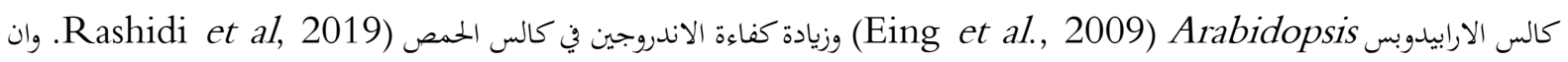

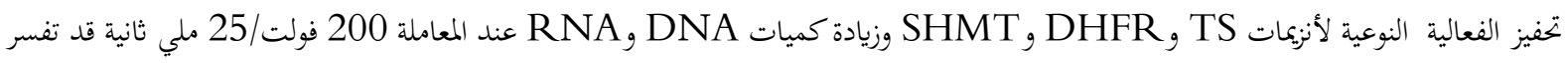
بأن هذه الصدمة حفزت تكوين ثقوب دقيقة مؤقتة في الغشاء البلازمي والجدار الخلوي تسهل دخول الايونات والمغذيات من الوسط إلى داخل الخلايا

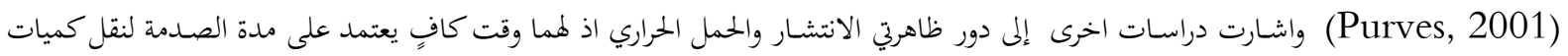

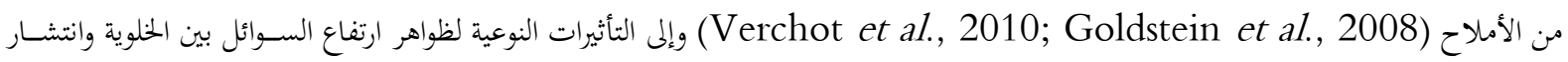
المحاليل داخل الخلية المهمة متضـمنة electrolysis gectro-osmotic ومسـاهتهما في زيادة استقطاب الخلايا لاحتياجاتما الغذائية لإنجاز

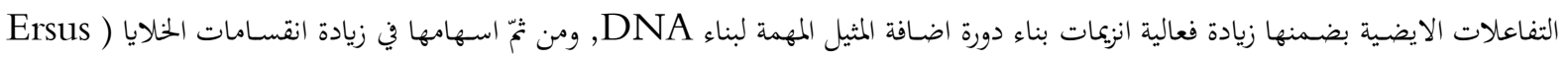

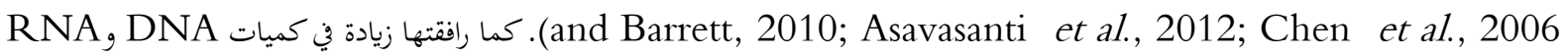

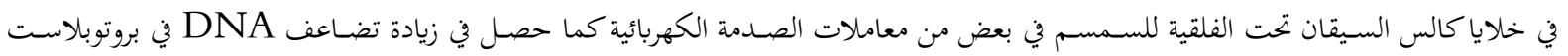
الخلايا (Rech et al., 1988). في هذه الدراســة قد يعزى تماثل انماط الزيادة في فعالية انزيمات SHMT, DHFR, TS وكميات الاماض RNA, DNA والبروتين في خلايا الكالس مع انماط الزيادة في تركيز الفوليت في خلايا كالس السيقان تحت الفلقية للسمسم, الى دور حامض الفوليك ومشتقاته في بناء نيوكليوتيد

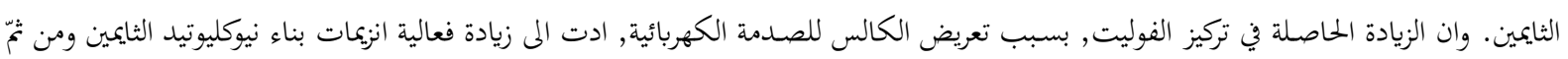

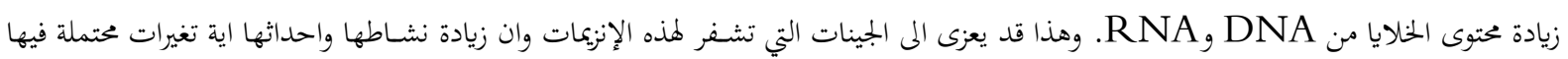

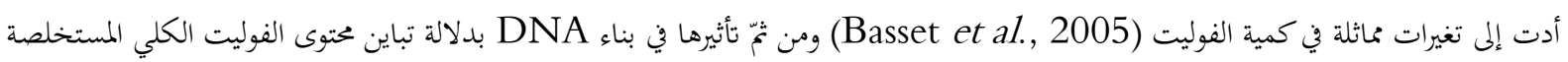
من أنسـجة كالس السـيقان تحت الفلقية مقارنة بتركيزه في أنسـجة السـيقان تحت الفلقية للبادرات المعقمة. ويمكن القول أن التباين في تركيز الفوليت

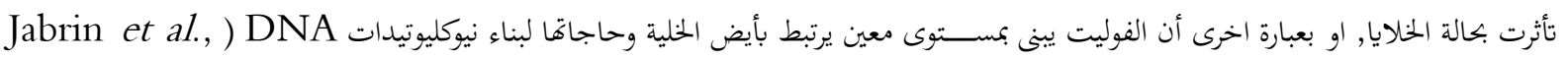

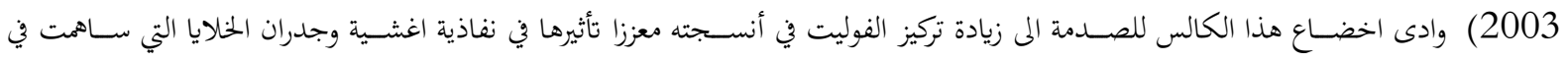

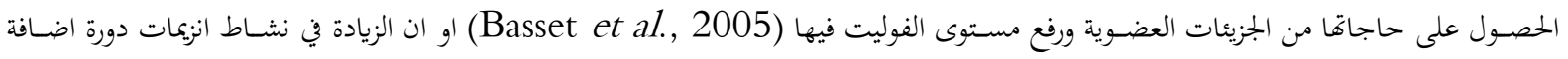

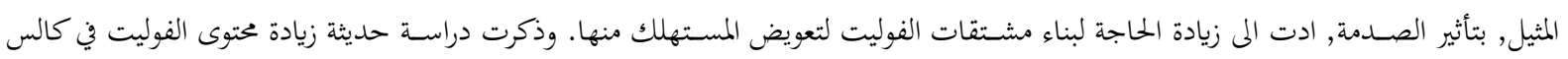

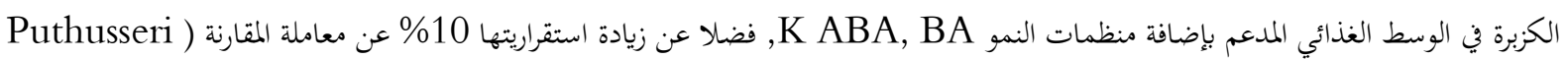

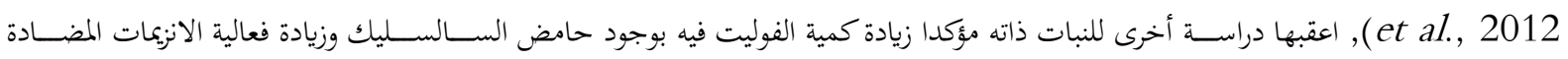
للأكسدة (Puthusseri et al., 2013). وأيدّت دراسة أخرى التغيرات في محتوى RNA, DNA والبروتين في كالس نبات الخس ( محمد مرد 


\section{Global Proceedings Repository \\ American Research Foundation}

ISSN 2476-017X

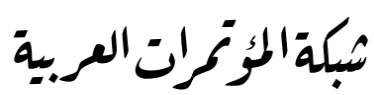

http://arab.kmshare.net/

Available online at http://proceedings.sriweb.org

وأخرون, 2007) وكالس السـمسـم (عمد وعبود، 1995). ان الافتراضـات اعلاه تؤكد دور مركبات الفوليت في بناء الأحماض النووية والبروتينات بسـبب مشــاركتها في بناء نيوكليوتيدات البيورين والثايمين وبعض الأماض الأمينية. وأن التعرض لعوامل فيزياوية لا يؤدي فقط إلى تغير في الصـفات

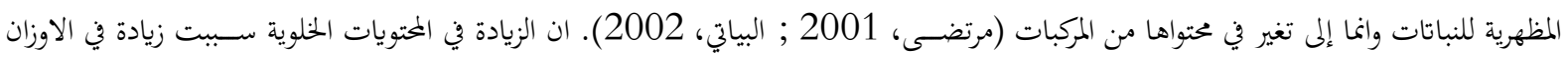
الرطبة للكالس ، قد يعزى هذا المى دور مركبات الفوليت في اكمال بناء حلقة البيورين واضــافة بمموعة المثيل لبناء نيوكليوتيد الثيمين احد اهم

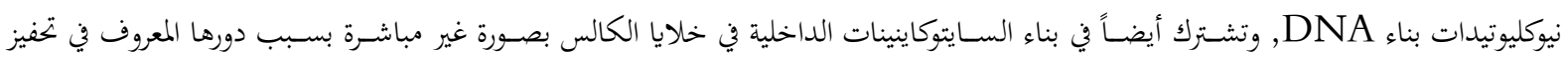

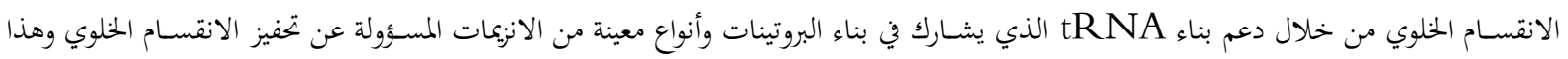
يؤكد حاجة خلايا الكالس إلى مركبات الفوليت لعمليات التوسع والانقسام (Smith et al., 1987).

أحمد، جاسم محمد ياسين (2000). التحول الوراثي في نباتات الحلبة Trigonella foenum-graecum بواسطة بلازميدات Ri و Ti لبكتريا Agrobacterium . رسالة ماجستير، كلية التربية، جامعة الموصل, العراق.

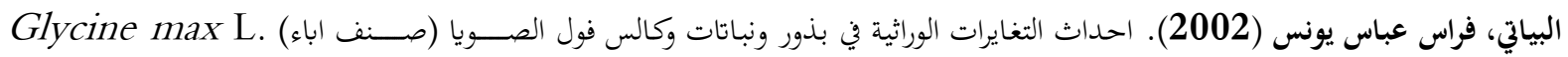

$$
\text { باستخدام أشعة كَاما و تأثيراتما في الختوى البروتيني ونسبة الزيت. رسالة ماجستير، كلية التربية، جامعة الموصل, العراق. }
$$

الطائي، نهال عزت (2005). التنقية الجزئية لإنزيم الكلوتاميت ديهايدروجنيز من كالس سيقان نبات الحبة السوداء .Nigella sativa Lبوجود

$$
\text { منظم النمو DDA 2, 4 2, 2 في الوسط الغذائي. رسالة ماجستير، كلية العلوم، جامعة الموصل, العراق. }
$$

الملاح, مزاحم قاســم (2002). ابتكار جهاز التحفيز الكهربائي (الجهاد1) وتطبيقاته في زراعة الانســـة النباتية. براءة اختراع 3033.

$$
\text { التقييس والسيطرة النوعية. جمهورية العراق. }
$$

محمد، عبد المطلب وعبود، سـاجدة عزيز (1995). تأثير بعض منظمات النمو على محتوى البروتين والأماض النووية واخلاف النباتات من كالس نبات السمسم .Sesamum indicum L. بجلة علوم الرافدين، 1: 1-12.

محمد, عبد المطلب, الجلبي , قصـي عبد القادر وعبود، ســاجدة عزيز (2007). عزل وتنقية جزئية لانزيم الثايميدليت ســينيز من كالس

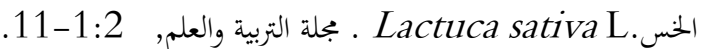

مرتضى، عبدالقادر اسكندر (2001). مقارنة صنفي القطن اشور وكركر 310 واستجابتهما لتأثير اشعة كَاما في مظاهر وانتاجية النباتات. رسالة ماجستير، كلية التربية، جامعة الموصل، العراق.

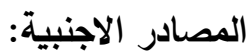

Al- Mallah, M. K. (1994). Electrostimulation of in vitro cultures. Agricell Repts., 22: 29-32.

Al- Mallah, M. K. and Salih, S. M. (2003). Electroporation increased growth of callus, regeneration capability and protein content of Solanum nigrum L. Plants. Raf. J. Sci. , 14: 35-42. 


\section{Global Proceedings Repository \\ American Research Foundation}

ISSN 2476-017X

Available online at http://proceedings.sriweb.org

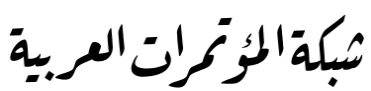

http://arab.kmshare.net/

AR F

Arnon, D. I. and Hoagland, D. R. (1944). The investigation of plant nutrition by artificial culture methods, Biol. Rev. 19: 55- 67.

Asavasanti, S. ; Stroeve, P. ; Barrett, D. ; Jernsted, J. and Ristenpart, W. (2012). Enhanced Electroporation in plant tissues via low frequency pulsed electric fields: influence of cytoplasmic streaming. AIChE. USA.

Al-Taweel, S.K.;Cheyed,S.H. and Al-Amrani,H.A.(2018).Effect of electrical shock on germination and seedling growth in henbane species,Academia Journal Medicinal Plants,6(5):071-078.

Basset, G. J. ; Quinlivan, F. P. ; Gregorg, J. F. and Hanson, A. P. (2005). Folate metabolism in plants. Crop. Sci. 45: 449-453.

Batra, K. K. ; Wagner, J. R. and Stokstad, E. L. R. (1977). Folic acid compound in romanine Lettuce. J. Bio Chem. 55: 865-868.

Blakley, R. L. (1969). The biochemistry of Folic Acid and Related Pteridines. American Elsevier Publishing Co, Inc. , New York.

Chen, C. ; Smye, S.W., Robinson, M. P. and Evans, J. A. (2006). Membrane electroporation theories: overview. Med. Biol. Eng. Comp. 44: 5-14.

Cherry, J. H. (1962). Nucleic acid determination in storage tissue of higher plants. Plant Physiol. 37: 670- 678.

Eing, C. J. ; Bonnet, S. ; Pacher, M. ; Puchta, H. and Frey, W. (2009). Effects of nanosecond pulsed electric field exposure on Arabidopsis thaliana. Karlsruhe Institute of Technology. 1322-1328.

Ersus, S. and Barrett, D. M. (2010). Determination of membrane integrity in onion tissues treated by pulsed electric fields: Use of microscopic images and ion Leakage measurements. Innovative food Sci. Emerg. Technol. 11: 598-603.

Friedkin, M. (1963). Thymidylate Synthetase, Adv. Enzymol. 38: 235- 292.

Gao, G. ; Sheng, X. and Li, X. (2010). Determination of folic acid in folic acid tablets by HPLC. J. Jining Medical University. Rizhao, China.

Gätjens-Boniche,O.; Díaz,C.; Hernández-Vásquez,L.; Chavarría-Rodríguez,P. and Martínez-Ávila,E.(2017). Effect of Electrical Current Applied in Soaking Conditions on Germination of Acacia and Maize Seeds, IOSR-JAVS, 10:11-18.

Giles, K. W. and Mayer, A. (1967). Determination of DNA concentration with diphenylamine reagent. Meth. Enzymol. 12: 163.

Goldstein R. E. ; Tuval, I. and Van De Meent, J. W. (2008). Micro fluids of cytoplasmic streaming and its implications for intracellular transport. Proc. Natl Acad Sci. 105: 3663-3667.

Gupta, S. D. and Y. Ibaraki (2008). Plant Tissue Culture Engineering. 417-462. Springer, Netherland. 


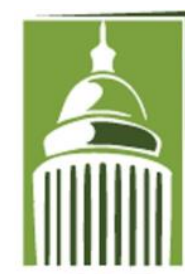

ARF
Global Proceedings Repository

American Research Foundation

ISSN 2476-017X

Available online at http://proceedings.sriweb.org

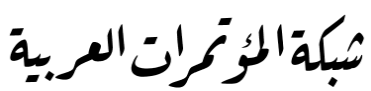

http://arab.kmshare.net/

Huennekens, F. M. ; Ho, P. P. K. and Scrimegour, K. G. (1963). Preparation and Properties of Active Formaldehyde and Active Formate. Eds. : Colowick, S.P. and Kaplau, N.O. Meth. Enzy. 6: 806- 811.

Jabrin, S. ; Ravanel, S. ; Gambonnet, B. ; Douce, R. and Rebeille, F. (2003). One- carbon metabolism in plants: regulation of tetrahydrofolate synthesis during germination and seedling development. Plant Physiol. 131: 1431-1439.

Joersbo, M. and Brunstedt, J. (1991). Electroporation: mechanism and transient expression, stable transformation and biological effects in plant protoplasts: Physiol. Plant. 81: 256-264.

Lowry, O. H. ; Rosebruogh, N. J. ; Farr, A. L. and Randall, R. J. (1951). "Protein measurements with the Folin reagent", J. Biol. Chem., 193: 265-275.

Mathews, C. K. ; Scrimgeour, K. G. and Huennekens, F.M. (1963). Dihydrofolic acid reductase. (Eds.: Colowick, S. P. and Kaplau, N.O.) Meth. Enzym. 6: 364- 368.

Mohammad, A. M. S. ; Al-Chalabi, K. A. and Abood, S. A. (1989a). The occurrence and properties of dihydrofolate reductase isolated from sunflower callus. J. Exp. Bot. 40:693-699.

Murashige, T. and Skoog, F. (1962). A revised medium for rapid growth and bioassays with tobacco tissue cultures. Physiol. Plant. 15: 473- 497.

Nakagawa, T. ; Shimada, M. ; Kurita, N. ; Lwata, T. ; Nishioka, M. ; Yoshikawa, K.; Higashijima, J.; and Wts Vnomiya, T. (2012). Thymidylate synthase (TS) protein expression as a prognostic factor in advanced colorectal cancer: a comparison with TS mRNA expression. Hepatogastroenterology. Department of Surgery, the University of Tokushima, Japan. 59: 1059- 1062.

Osborne, M. J. and Huennekens, F.M. (1958). Enzymatic reduction of dihydrofolic acid. J. Biol. Chem. 233: 969- 974.

Purves, W.K. (2001). Life: the science of biology. Sinauer Associates. 6: 316-317. India, 136: $569-75$.

Puthusseri, B. ; Divya, P. ; Lokesh, V. and Neelwarne, B. (2012). Enhancement of folate content and its stability using food grade elicitors in coriander (Coriandrum sativum L.). Plant Food Hum. Nutr. 67: 162-170.

Puthusseri B. ; Divya, P. ; Lokesh V. and Neelwarne, B. (2013). Salicylic acid-induced elicitation of folates in coriander (Coriandrum sativum L.) improves bioaccessibility and reduces pro-oxidant status. Food Chem.

Rashidi ,S; Abdollahi ,M; Sarikhani, H and Moosavi S. (2019). Investigation of the Effect of Centrifugation and Electrical Shock Pretreatments on the Androgenesis Efficiency in Chickpea (Cicer arientinum L.) Anther Culture. JMBS. 2019; 10 (2) :173-181 


\section{Global Proceedings Repository \\ American Research Foundation}

ISSN 2476-017X

Available online at http://proceedings.sriweb.org

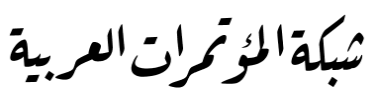

http://arab.kmshare.net/

Rech, E. L. ; Ochatt, S. J. ; Chand, P. K. ; Davey, M. R. ; Mulligan, B. J. and Power, J. B. (1988). Electroporation increases DNA synthesis in cultured plant protoplasts. BioTechn. 6: 1091-1093.

Salih, S. M. (2001). Enhancement of growth and regeneration ability of callus culture from Chamomile matricaria, chamomilla. J. Educ. and Sci. 53: 54-62.

Santi, D. V. and Danenberg, P. V. (1984). Folates in Pyrimidines nucleotide biosynthesis. In: Folates and Pterins . John Wiley and Sons, New York.

Silva, R. F. and Yuffa, A.M. (2003). Transient gene expression in secondary somatic embryos from coffee tissues electroporated with the genes gus and bar. Elect. J. Biotech. 6 : 3414-3428.

Smith, K. H. ; Kerns, H. A. ; Antony, J. L. and Wild, J. R. (1987). Methotrexate and aminopterin effects on growth and regeneration in Daucus carota. Plant Cell Repts. 6:60-62.

Uyeda, K. and Rabinowitz, J.C. (1968). Enzymes of the clostridial purine fermentation serine hydroxymethyl transferase. Arch. Biochem. Biophys. 123: 271- 278.

Verchot, L. ; Lubicz, J. and Goldstein, R. (2010). Cytoplasmic streaming enables the distribution of molecules and vesicles in large plant cells Protoplasma. 240: 99-107.

Vorobiev, E. and Lebovka, N. (2008). Pulsed- Electric- Fields- Induced Effects in Plant Tissue: Fundamental Aspects and Perspectives of Applications. Electro technologies for Extraction from Food Plants and Biomaterials. France Springer. Science Business Media. 39-78.

Yeom, H. W. ; Streaker, C. B. ; Zhang, Q. H. and Min, D. B. (2000). Effects of pulsed electric fields on the activities of microorganisms and pectin methyl esterase in orange juice. J. Food Sci. 65: 1359-1363. 